\title{
FIREWORTHINESS OF TRANSPORT AIRCRAFT INTERIOR SYSTEMS
}

\author{
John A. Parker and D. A. Kourtides
}

Ames Research Center

INTRODUCTION

This paper presents an overview of certain aspects of the evaluation of the fireworthiness of air transport interiors. First, it addresses the key materials question concerning the effect of interior systems on the survival of passengers and crew in the case of an uncontrolled transport aircraft fire. Second, it examines some technical opportunities that are available today through the modification of aircraft interior subsystem components, modifications that may reasonably be expected to provide improvements in aircraft fire safety. Cost and risk benefits still remain to be determined.

Space permits only the discussion of three specific subsystem components: interior panels, seats, and windows. By virtue of their role in real fire situations and as indicated by the results of large-scale simulation tests, these components appear to offer the most immediate and highest payoff possible by modifying interior materials of existing aircraft. These modifications have the potential of reducing the rate of fire growth, with a consequent reduction of heat, toxic gas, and smoke emission throughout the habitable interior of an aircraft, whatever the initial source of the fire. It will be shown that these new materials modifications reduce the fire hazard not only because of their unique ablative properties, which help to contain or isolate the fire source, but also because there is a significant reduction in their characteristic flame spread, heat release, and smoke and toxic gas emissions.

\section{SURVIVABILITY CRITERIA FOR AIRCRAFT FIRES}

Significantly destructive fires, which have been encountered by transport aircraft, can be classified generally into three kinds (fig. 1): the in-flight fire, the ramp fire, and the survivable postcrash fire. Historical surveys taken over periods of 10 to 15 years for a variety of aircraft under a wide range of operating conditions have shown that the postcrash fire accounts by far, perhaps by a factor of 10 , for most of the aircraft fire deaths. As indicated in figure 1 for a 270 passenger aircraft, the probable interaction of the 37,000 to 75,000 liters of jet fuel and ignition sources generated by damaged engines produces a fire source that interacts with the airframe and then with the interior systems to introduce the survivability fire parameters 1 isted in the figure. The in-flight fire, whatever its source, can interact directly with the interior subsystems to ignite and cause them to burn. 
It is a basic premise of all subsequent arguments that any vehicle interior will become a totally lethal environment if the fire source is large enough. It is also tacitly assumed that any and all material subsystems of an aircraft interior comprising organic polymeric materials (as shown as fuel load in fig. 1) can also contribute by means of (or may be limited by the fire parameters shown) to the formation of a lethal environment if the fire source and fire growth rate are sufficiently large. It is really unimportant when considering the flammability of the aircraft interior whether the fire source derives from, for example, the ignition of spilled fuel, a cargo bay fire, or arson. What is important, however, is how flammable the interior subsystems are and how large a fire source is encountered. Effects of crash impact on human survivability and of vehicle crashworthiness on the growth of the fuel fire have not been considered in this paper. Only the time rate of change in cabin temperature and the concurrent release of smoke and toxic gas from the combination of the fire source and the fire involvement of the interior have been considered as significant factors in establishing allowable egress times for passengers and crew members. It has been a goal of NASA's "FIREMEN" program to improve the allowable egress time by a factor of 2, that is, from 2.5 to 5 min, by modifying the materials used in aircraft interior subsystems to better understand the conditions imposed by postcrash fuel fire sources.

The ground rules of the SAFER Committee (ref. 1) excluded the in-flight fire case from considerations. This limited somewhat their specific recommendations concerned with the fireworthiness of aircraft interiors systems, such as toxic fume hoods, and fire-fighting methods. The Federal Aviation Regulation (FAR) burner flammability test remains as a recommendation which all must agree has not been related to materials aircraft fire safety. It is reasonable to infer from the foregoing that once an interior system has been ignited with a sufficient fire source that the survival time for the in-flight case can be closely related to the allowable egress time in the postcrash case.

The SAFER Committee has postulated that the evidence from aircraft fire death statistics makes in-flight fires relatively insignificant and that only postcrash fires deserve immediate attention. Postcrash fires cause about 30 deaths per year; recent congressional testimony (ref. 2) suggests that there have been over 300 fire deaths in in-flight fires since 1969. About 419 fatalities are attributed to survivable postcrash fires during the 1969-1978 period according to the same testimony. This recent record of in-flight events should moderate an exclusive interest in postcrash fires. SAFER made two other assumptions: (1) that the principal fire source in aircraft fire deaths is that arising from ignition of a misted-fuel cloud resulting from tank rupture during impact; and (2) that the heat, smoke, and toxic gases produced by the burning fuel are principal factors in the formation of a lethal cabin environment. One might conclude, after considering these two assumptions, that the fireworthiness of aircraft interiors may be a matter of little concern in most cases, and, indeed, current activities with antimisting kerosene (AMK) correctly reflect this hypothesis and dominate the SAFER recommendation. SAFER, however, did endorse full-scale simulation of survivable postcrash fires, using a C-133, as a means of assessing the role of the fuel fire on human survivability. Recent results from $\mathrm{C}-133$ tests (to be discussed below), reported in reference 3 , seem to indicate that the flammability of interior systems may be the principal factor in the allowable egress time, even in the postcrash 
fire. Detailed analysis of the fireworthiness of transport aircraft incidents (ref. 4) indicates that under many conditions the flammability of interior systems may be significant in postcrash as well as in-flight aircraft fires. Recent fires in both rapid ground transportation and transport aircraft suggest that under the appropriate conditions, vehicle interiors are destructively flammable, independent of the nature of the large fire source.

\section{INTERIOR SYSTEMS FROM A FIRE POINT OF VIEW}

There are two identifiable, distinct, and separate thermochemical mechanisms by which interior materials systems can interact with a given fire source. These mechanisms have been defined in this paper as fire isolation (containment) and fire involvement. The first interaction depends only on the ablation efficiency of the material subsystem component; the second depends on combustion mechanisms that have been shown to depend on the pyrolysis vapor production rate and on the composition of the pyrolysis gases.

Neel et al. (ref. 5) have demonstrated, in a full-scale test with an intact $\mathrm{C}-47$ fuselage, that the lethal effects of a complete burn with an 18,925-1iter fuel fire source can be completely excluded from the aircraft interior by means of a lightweight organic ablative foam applied to the aircraft interior skin. No protection from fire penetration is provided by current plastic-bagged fuselage insulation. At present this ablative insulation systems approach has not been found practical by aircraft manufacturers. Kourtides et al. (ref. 6) have demonstrated in full-scale fire containment tests against simulated fuel fire sources, that ablative foams or honeycomb fillers and edge closeouts can effect as much as a fivefold improvement in the fire containment capacity of various kinds of aircraft panels, such as ceilings, walls, lavatories, and cargo bays, while at the same time maintaining the required structural strengths without an appreciable weight penalty.

Here then is a simple, available, and producible new kind of aircraft panel concept ready for application. It is believed that inert ablation efficiency of these new panel systems may be particularly effective in controlling fires in unattended areas of the aircraft. One need only optimize (modify the foam density) the ablation efficiency of these panel structures to provide the required containment times to a designed back-face temperature, probably about $200^{\circ} \mathrm{C}$ for the expected heat load from probable fire sources. Specific examples of applying the ablative fire-containment method to the fire-blockinglayer concept in aircraft seating and window systems will be described further in this paper.

Fire involvement, largely dependent on material pyrolysis and flammability, is a somewhat separate matter from ablative fire containment. Fire involvement comprises the interaction of a number of factors that contribute to the generation of lethal cabin conditions - ease of ignition, flame spread rate, heat release, and smoke and toxic gas emission. A11 of these factors interact cooperatively to reduce the probability either of passengers escaping or surviving when trapped. These properties depend on the thermochemical properties of the basic polymer out of which the component has been constructed 
as well as on the size and intensity of the applied fire source. Unfortunate1y, most usual laboratory flammability tests (ref. 7) have been carried out at cold-wall radiant heating rates of $2.5 \mathrm{~W} / \mathrm{cm}^{2}$ or less. As will be discussed below, it has been found that the combustible vapor production rate at the wal1 of the material is the controlling rate process for all of the fire involvement factor. This controlling rate is an intrinsic property of the material and of the applied heating rate. A heating rate of $2.5 \mathrm{~W} / \mathrm{cm}^{2}$ is much too low to characterize materials in the usual fire environment, in which case heating rates are found to vary from as little as $0.5 \mathrm{~W} / \mathrm{cm}^{2}$ to as much as $14 \mathrm{~W} / \mathrm{cm}^{2}$.

A typical example of an aircraft panel construction is shown in figure 2 . Current films, inks, substrate films, and face sheets are made up of as much as $25 \%$ of contemporary materials of low char yield polymers (to be explained below). They are characterized in terms of ease of ignition by the standard limiting oxygen index test with values from 16 to 23 (percent oxygen in the ignition mixture required for sustained burning with an ignition source of about $1-2 \mathrm{~W} / \mathrm{cm}^{2}$ ). One should expect them to burn in air under the sustained fixe impact of less than $2 \mathrm{~W} / \mathrm{cm}^{2}$ and to burn with increasing rates as the fire source is increased.

Standard panels of this kind were evaluated by Parker et al. (ref. 8) in a ful1-scale lavatory mock-up using a 2.5-kg hydrocarbon fuel source, with unrestricted ventilation. The fire source burned for about $10 \mathrm{~min}$, with an average peak heating rate of about $8 \mathrm{~W} / \mathrm{cm}^{2}$, typical of a moderate aircraft trash fire. The lavatory panels, when exposed to this critical fire size, lead to flashover which produces a totally lethal environment in different size structures with different materials.

It was concluded from these tests that the high vapor production rate for low-char-yield materials comprising the decorative surfaces and face sheets coupled with this critical fire size combined to achieve this fatal condition. Characterization of the survivability at fire sizes with this lavatory system at less than the critical flashover fire size seems to depend on all the factors listed above that describe the total fire involvement.

Currently, attempts are being made to arrive at a "combined hazards index" or CHI (ref. 9) comprising the lethality of a material exposed to a fire source less than the flashover critical size; the index would combine the rate of heat released, the smoke obscuration, and time to incapacitation due to toxic gas emissions. So far this has required very complex testing, involving animal exposures, variable heating rates, and complex computer data reduction for fire models which depend on vehicle geometry and a presupposed fire scenario.

What is needed is a simple test for materials suppliers and users alike which would permit the selection of polymeric components for design and construction of system components on the basis of the components' enhancement of survivability in an aircraft fire. Parker and Winkler (ref. 10) showed earlier in 1967 that the anaerobic char yield could be estimated from the polymer structure and the cross-linking reactions of the polymer at elevated temperatures. It may be safely inferred from the foregoing that the tools 
exist with which to design and synthesize polyuers with any set or limiting set of fire-involvement properties that the application demands.

Later, Kourtides (ref. 11) and van Krevelen (ref. 12) showed that these char-yield rules could also be applied to calculating the limiting oxygen index (LOI) of thermoplastics in addition to the thermoset system described by Parker and Winkler (ref. 10). Kourtides et al. (ref. 13) took advantage of this rule by developing criteria for selecting thermoplastic molding components for aircraft applications by correlating a linear combination of fire involvement properties with the measured anaerobic char yield. It was also found that when atoms such as chlorine, bromine, sulfur, fluorine, or nitrogen are contained in the polymer, a simple correction in the proportionality constant relating char yield to LOI could account for the variation in flammability properties of the neat polymer. As far as polymer selections are concerned, Fish and Parker (ref. 14) first showed that as long as the polymer did not melt and flow (as do, for example, epoxides, urethanes, and phenolics) all of the significant fire involvement properties of the bulk polymers, such as flame spread rate, ease of ignition, smoke obscuration, and toxic gas production, vary in a regular way (usually linearly) with the vapor production rate of the polymer being heated. Moreover, Fish and Parker showed that this relative vapor production rate can be accurately determined by the simple thermogravimetric analysis of the anaerobic char yield.

In figure 3 it can be seen that the simple and single value of the char yield can readily be used to rank the fire involvement characteristics of individual polymers for selection of candidates for the fabrication of interior system components. It turns out that the materials flammability properties, such as net heat released and the amount of smoke and gas generated at a fixed heating rate (radiative cold wall), are all unique and regular functions of this easily measured or calculated anaerobic char yield value. It should be pointed out, however, that what one is concerned with in estimating the probability of survivability is the rate of the production of these lethal products.

Even though the char yield as defined is more or less independent of the applied heating rate, the rate of char formation and the related flammability properties are determined by the ablation rate, which in turn increases with increasing heating rate. Because the material will encounter a variable heating rate, depending on scenario, SAFER (ref. 1) has recommended that these relative rates should be determined in the ohio State heat-release calorimeter, in which the heat release and other rates can be measured at variable heating rates. Presumably these rates then can be used to construct any desired heating rate curve to estimate the time-dependent rates of heat, smoke, and gas production. Since these rates may be expected to vary with the thermal history of the sample and with the nature of the flame chemistry, we have preferred to use a propane burner; the burner can accurately simulate the actual timedependent heating rate functions with a reasonable simulation of the firesource flame chemistry. Initial screening of samples may be done with radiantpanel sources at a fixed average heating rate at $5-10 \mathrm{~W} / \mathrm{cm}^{2}$. The measured rates in radiant-panel tests related to a real and variable heat source can be determined by a propane gas burner preprogrammed to simulate the time-dependent heating rate encountered with a real fire source. For most cases that involve the fuel fire sources encountered in aircraft fires, the flammability of 
materials systems can be compared by means of a radiant panel providing an average heating rate of $5-8 \mathrm{~W} / \mathrm{cm}^{2}$, with pilot flame ignition. These results can be correlated with the measured anaerobic char yield, which usually gives a reasonable measure of the combined hazard index. Correlations with char yields have been reported in many studies, and Hilado et al. (ref. 15) have stated that this method is adequate in $90 \%$ of the cases studied. On a charyield scale from zero (polymethylmethacrylate) to 100 (graphite), most contemporary aircraft materials are rated at less than 23 , whereas the advanced materials offered in this paper all have values greater than 35 . The latter are virtually nonflammable in air and produce little or no smoke or toxic gas.

The ablation efficiency in the fuel-fire environment of bulk polymers and their component derivatives is a different matter, as shown in figure 3 . In this case the ablation efficiency increases with increasing char yield from about $23 \%$ to about $50 \%$, after which it decreases abruptly. Although most of the flammability properties continue to decrease at char yields greater than $50 \%$, it has been found that materials with char yields between $45 \%$ and $60 \%$ give the best combination of fire containment and fire involvement properties. Since it is probably true that the ablation efficiency is the principal parameter that governs the change in heat release, smoke, and toxic gas production rates, as these rates vary with applied heating rate, it is not surprising that the polymers, such as phenolics, bismaleimides, and others with char yields in the range of 45 to 60 , show very low rates that change very 1 ittle over an applied heating rate range from 3 to $10 \mathrm{~W} / \mathrm{cm}^{2}$. If it were possible to restrict the choice of advanced aircraft materials to this char yield range, which gives the best combination of fire-resistant properties, correlation of existing laboratory tests with full-scale performance would be highly simplified.

A rather simple correlation of the fire ablation efficiency of experimental aircraft panels in which the face sheets have been modified by choosing high char yield resins is shown in figure 3 . The test method has been described by Riccitiello et a1. (ref. 16). Here, comparable panels are exposed to a combined radiant and convective source, which has been found to correlate well with a full-scale fuel test. In the figure, the time to back-face temperature rise has been plotted as a function of the exposure time in seconds. The time required to reach a back-face temperature of $200^{\circ} \mathrm{C}$ has been selected to complete the relative fire ablation efficiencies of the candidate panels. It can be seen, as anticipated by the general trend in fire ablation efficiency of the face-sheet matrix resin composites, that the low-char-yield epoxies and the highest-char-yield conventional polyimides, with char yields of $23 \%$ and $70 \%$, respectively, gave the shortest times to back-face temperature rise to $200^{\circ} \mathrm{C}$; the bismaleimides and phenolics with char yields of the order of $45 \%$ to $60 \%$ gave the best performance.

Candidate phenolic and bismaleimide panels selected from this screening study were evaluated by Williamson (ref. 17), in full-scale fire-containment tests in which a variable propane burner was used to simulate the effect of actual burning of aircraft trash bags. It was found that the best fire retarded epoxy panels as baseline with face-sheet resin char yields of $23 \%$ reached a back-face temperature of $200^{\circ} \mathrm{C}$ in about $5 \mathrm{~min}$, whereas the bismaleimide and phenolic panels with a peak heating rate of $6.5 \mathrm{~W} / \mathrm{cm}^{2}$ contained the simulated fire for as much as 15 min at a back-face temperature of $200^{\circ} \mathrm{C}$. 
On the basis of these tests, a ful1-scale wide-body transport lavatory was fabricated of phenolic panels (fig. 4). The fire-containment capability of this lavatory with the door closed and with the normal ventilation rate was evaluated in the Douglas cabin fire simulator (CFS). A sustained fire, which reached a peak heating rate of $12 \mathrm{~W} / \mathrm{cm}^{2}$ in $10 \mathrm{~min}$, was started in the lavatory, using simulated aircraft trash. The fire burned itself out in about $1 \mathrm{hr}$. The effect of the fire on the lavatory is shown in figure 4. The only evidence of any lack of containment is shown in the figure as a slightly scorched area along the door edge. It is believed this slight fire penetration was a result of the limited fire containment of a small amount of polyurethane foam used at the edge of the door, a problem that can be easily corrected by replacing the polyurethane with phenolic foams. The slight damage did not propagate the fire. Otherwise the panels did not burn through or reach back-face temperatures in excess of $200^{\circ} \mathrm{C}$ over most of their surfaces.

No significant toxic gas was observed in the adjacent cabin area, as evidenced by the survival there of an animal (rat) test subject. A completely survivable environment existed within the cabin for $1 \mathrm{hr}$; animal subjects survived that period without adverse effects.

It can be concluded that the panels fabricated from the phenolic resins did an adequate $j o b$ in containing a substantial compartment fire. However, the fact that most of the lavatory outer surface did not reach the design temperature of $200^{\circ} \mathrm{C}$ suggests that the fire protection ablative system was not fully exploited in this test. It is clear from various studies that the burn times and peak heating rates are controlled by the ventilation rate and the amount of fuel and its distribution in the compartment. One might say that the size of the fire in the test (fig. 4) was conservative. The simulation results with the propane gas burner support a conclusion that these panels could be expected to contain a compartment fire of a much greater severity for 3 to 5 times as long as the standard epoxy panels. The phenolic panels should be able to provide a margin of safety at least 3 times greater than the epoxy panels. This is especially important since similar panel construction is used throughout the aircraft interior where more severe fire sources (postcrash fires) may be encountered, for example, in cargo bays and side wall and ceiling panels.

The effects of face-sheet matrix resin type on the time required for complete fire involvement in a simulated cabin compartment were evaluated in a large-scale flashover fire test facility (fig. 5). A flashover fire test facility was constructed as a modification of the corner test described by Williamson (ref. 17). A ceiling extension panel constructed of the same materials as the wall panels was included. The propane burner shown in the corner, which had been calibrated with aircraft trash bags by metering the propane gas flow, was used as a fire source. The heating rate changes with time, as measured by calorimeters installed in the walls and ceiling, duplicated those of the aircraft trash bags. An arbitrary flash-over criterion was adopted as the time for the center ceiling thermocouple No. 57 to reach $500^{\circ} \mathrm{C}$. In a baseline test with Transite (noncombustible and thermally inert), $500^{\circ} \mathrm{C}$ was reached in about $2 \mathrm{~min}$; this value is represented in figure 6 as T3. With ceilings and wall panels constructed of standard epoxy, the critical temperature of $500^{\circ} \mathrm{C}$ was reached in less than $30 \mathrm{sec}$ (T0) as observed on thermocouple No. 57, the 
process being accompanied by large amounts of dense smoke, shown in a separate test, to be largely due to the epoxy resin component of the panel. Next, a fire retardant epoxide panel was evaluated which extended the flashover time to more than $50 \mathrm{sec}$ (T1). As expected with fire-retardant additives, enormous amounts of dense black smoke were generated from these panels almost immediately, but the flashover time was extended by a factor of 2 .

Similar constructions were tested using the same phenolic and bismaleimide panels as those used in the fire-containment tests described by Williamson (ref. 17) using the same fire scenario. Very little smoke was observed in either test. The phenolic panels gave a ceiling temperature of $500^{\circ} \mathrm{C}$ in $60 \mathrm{sec}(\mathrm{T} 2)$, and the bismaleimide gave a flash-over time greater than $90 \mathrm{sec}$ (T3), the bismaleimide panel being somewhat less resistant to total involvement than the inert Transite panels. In this test, an improvement by a factor of 3 for the time to full fire involvement was observed in comparing the state-of-the-art epoxy panel with the advanced bismaleimide panel; moreover, there was virtually no smoke obscuration. It remains to be seen if a similar relationship will hold for full-scale testing of these advanced panels in the $\mathrm{C}-133$.

It is of interest to see if the flashover times in this test can be correlated with the anaerobic char yields of the constituent resins and the respective oxygen indices. A best correlation was obtained by plotting the product of the time to flashover, $T$, and the applied heating rate observed at that time due to the burner fire source, as a function of the observed anaerobic char yield or limiting oxygen index. The change in the shape of the fire response curve approaches the limit for the inert Transite. It is interesting to note that the intermediate char-yield materials, the bismaleimide and the phenolic (45-60\%), show the same relative ranking in this test as that observed in the fire-containment case. This suggests that not only the char yield but also the fire ablation rate of char formation (slower in the case of the bismaleimides at these heating rates) are factors in the time required for full fire involvement. Even though both face-sheet matrix resin systems produce little observable smoke and presumably low levels of toxic gas, the best panel as determined in both fire-containment and fire-involvement studies seems to be the one derived from the bismaleimide.

At present, the phenolic resin system is the one of choice mainly due to resin costs and processibility. Anderson et al. (ref. 18) have shown that a positive cost benefit can be derived from using this phenolic panel system. This report details the result of a contractual program with the Boeing Commercial Airplane Company to examine the fire characteristics of sandwich panels, using laboratory-scale test procedures. The program had the multiple objectives of improving flammability, smoke emission, and toxic gas emission characteristics of sandwich panels without sacrificing manufacturability or mechanical or aesthetic qualities of the panels.

Figure 2 shows a typical configuration of a sandwich pane1 considered in the Boeing program. The various laminating resins and the test matrix used for these panels are also shown in this figure. 
A full matrix of testing was acomplished and the test results were combined mathematically with material and fabrication costs to arrive at a relative ranking of the candidate materials. The mathematical procedure utilized a weight distribution of parameters (fig. 7); this ranking method identified phenolic as the preferred resin system.

Figure 8 shows the contrast between flame-retardant epoxy resin and phenolic resin sandwich panels with respect to flammability, smoke, and toxic gas emission characteristics. It illustrates the improvements that phenolic resins exhibit over the baseline epoxy system.

Figure 2 is an example of a sandwich panel constructed with a phenolic resin. This construction, similar to that of a 747 partition panel, uses Tedlar (polyvinyl fluoride) as the decorative surface.

Phenolic resins have subsequently been developed further and will be used in the new generation commercial aircraft (e.g., 757 and 767). They will be utilized in a sandwich panel composite configuration, but it will be a crushedcore design concept. This provides for use of the weight advantages of sandwich panels while allowing more intricate contours to be achieved.

Figure 9 shows an example of a crushed-core sandwich panel; the panel shown is similar to that which will be utilized on the 757 and 767 aircraft.

\section{ADDITIONAL REMARKS ON PANEL SYSTEMS AS CEILINGS}

The results of the postcrash fire simulation with contemporary materials in the C-133, which will be discussed below, focus attention on the role of the flammability of ceiling panels in propagating the fire, once the fire is started by burning seats. In figure 2, it can be seen that in addition to the composite face sheets, contemporary panels also comprise a decorative surface system that consists of an outer layer of clear polyviny 1 fluoride, PVF, and interlayers of additional PVF, acrylate inks, and adhesives. All of these materials are highly flammable. They are present in such small amounts in comparison with the composite matrix resin that they contribute very little to the time to flash-over in the tests already described. However, as mounted horizontally above the seats, they ignite and drip as flaming debris and promote the rapid propagation of the fire throughout the aircraft interior. Even if the new fire-resistant seat is not ignited directly by the intrusion of the fuel fire, direct contact with the ceiling structure may spread the fire rapid1y.

Durable, transparent thin films - easy to process by existing decorating methods and with the same excellent maintainability characteristics as contemporary materials - have been exceedingly difficult to find. Although research at Ames has discovered a large number of high-char-yield transparent films that are finding wide application in aircraft windows and military canopies, none of them has the combination of properties required. New polymer research at Ames has identified several candidate polymers generally 
related to polyesters and polycarbonates that may be long-term solutions. A new high-char-yield polyether-ether-ketone (PEEK) (ref. 19) now being developed is an outstanding candidate to replace the existing polyvinyl fluoride film component. The PVF film has been found to give as little as $18 \%$ char yield with a limiting oxygen index of $16 \%$, whereas the new polyether-ether-ketone gives values of $45 \%$ for the char yield and a limiting oxygen index of $37 \%$, properties that are theoretically very close to ideal from a flammability point of view. This new film, intended for at least ceiling applications, has been also found to exhibit excellent maintenance characteristics. It will have to be applied with fire-resistant adhesives and inks. Two new polymers have been discovered which may serve this purpose. New fire-resistant ink and adhesive systems based on phosphorylated epoxides and tetrabromoepoxy acrylates are being developed by Kourtides, Parker et al. (ref. 20) to meet these special requirements. In the short term, fire-resistant bismaleimide composites, decorated with an ablative coating or with no decorative system, may be required for the highly fire-sensitive ceiling gases.

Summarizing the panel research and technology program developed under the NASA "FIREMEN" program at Ames Research Center, we have shown that the theory, materials, laboratory tests, large-scale tests, and production-ready pane1s with which it would be possible to screen, select, and provide advanced panel systems - are available. And it is known that the advanced panels have a reasonable probability of enhancing human survivability when the interior system of a transport aircraft is subjected to a substantial fire source, whatever its origin. What remains to be done to establish the fireworthiness of these advanced panels is to evaluate them in all full-scale tests of a cabin interior system in the FAA C-133 simulator, using the impact of a real fire threat drawn from likely scenarios. On the basis of heat, smoke, and toxic gas evolved, including the time to full fire involvement, it is anticipated that the increase in allowable egress time will be determined.

POSTCRASH FIRE SIMULATIONS IN THE C-133

Although planned for (ref. 21), there are no satisfactory models for the postcrash fire. Hill and Sarkos (ref. 22) have designed an empirical test that is based on three levels of severity with respect to fire penetration and ignition of the interior systems. Their purpose is to answer the question: "Does the severity of the external fuel fire so dominate the available egress time that the inherent flammability of contemporary systems contributes little or nothing to the available egress time?" Stated otherwise: What is the costbenefit in modifying the fuel system versus modifying the interior aircraft system? It is certainly not possible to make this trade-off at this time. However, the $\mathrm{C}-133$ test method provides a means of uncoupling the survivability effects of spilled ignited fuel from those of the interior materials system.

This full-scale mock-up, as described by Hill and Sarkos (ref. 22), is shown in figure 10 . It comprises a carefu11y simulated and instrumented C-133 fuselage to permit the evaluation of the external pool fire at three different levels of fire intensity within the fuselage. A fire representing an infinite 
fire course is created by a $1.2-$ by $1.2-\mathrm{m}$ ( $4-$ by 4-ft) fuel pan placed in front of the open forward door. This opening may simulate some average damage to the aircraft fuselage during a crash-survivable fire with an open door and permits radiation-on1y penetration of the fuselage under a zero-wind condition. The transfer of heat and mass from the fuel fire is said to be rate-determined by the direction and velocity of the wind at the door.

Only the zero-wind condition (the mildest condition) will be referenced in this paper. An evaluation of this condition, namely about $14 \mathrm{~W} / \mathrm{cm}^{2}$ at the doorway is found to decay to about $0.5 \mathrm{~W} / \mathrm{cm}^{2}$ at the aircraft centerline. The evaluation of the interior environment in the absence of interior aircraft systems suggest that between 5 and $10 \mathrm{~min}$ are available for the passengers to escape from the unfurbished aircraft. However, when a simulation was conducted with 16 seats in typical rows with paneling and mock-up thermoplastic occupying about $10 \%$ of the aircraft, it was found that the fire that ensued might reduce the egress time to less than $2 \mathrm{~min}$.

One may draw two conclusions from the above: (1) that as far as the qualifying materials for the effect of postfire environment the bunsen burner flammability test does not represent the above; and (2) at least under these conditions, the fire involvement characteristics of the interior materials play a large role in determining the human survivability at least in this scenario.

PROPAGATION OF THE FIRE CHAIN IN THE C-133 POSTCRASH FIRE SIMULATION

A tentative mechanism for the propagation of the fire chain due to the impact of the external fuel fire has been made by Eklund (ref. 23). It has been suggested that the wool-and-nylon-covered polyurethane cushions nearest the door are ignited by a radiant heat pulse with a radiative input greater than $8 \mathrm{~W} / \mathrm{cm}^{2}$, even in the absence of free flame. This threshold has been verified by HartzelI (ref. 24) in separate radiant panel tests. Once ignited, the fire from the seat reaches the ceiling panels; quickly thereafter the so-called "two zone effect," that is, downward radiation of the heat from the hot gas layer, ignites the remaining seats and a complete fire involvement ensues. Based on this scenario significant attention has been given to a short-term fix by applying a fire-blocking layer to the outboard seats. It is believed that the use of a highly efficient elastomeric ablative material, used for thermal protection for the extremely flammable urethane cushioning, may be sufficient.

SEAT DESIGN AND DEVELOPMENT BASED ON COMPONENT RESPONSE TO THE POSTCRASH FIRE

It is clear from the foregoing $\mathrm{C}-133$ test results with contemporary materials in a zero-wind postcrash fire simulation that ignition and burning of the outboard seats seems to be the principal fire source inside the cabin. It has been shown by Bricker and Duskin (ref. 25) that the extremely rapid burning 
of aircraft seats is due to the polyurethane cushions of the seats. Little benefit can be obtained by making the polyurethane fire retardant. Either the polyurethane elastic foam must be replaced with a completely fire-resistant cushioning foam or the polyurethane must be protected by a compatible fireblocking ablative material. Both of these approaches are being investigated in efforts to find ways of breaking the fire chain and restricting the spread of the fire throughout the interior of the cabin.

The ablative efficiency of foamed polychloroprene (neoprene) as a fireblocking layer to protect military aircraft fuel tanks against external pool fires was first demonstrated by Pope et al. in 1968 (ref. 26). Foamed neoprene is currently the ablative material of choice, specifically low-smoke L-200 neoprene, because of its high charring ablation efficiency, moderate cost, and availability. Neoprene cushioning cannot be fabricated at useful densities much less than $46 \mathrm{~kg} / \mathrm{m}^{3}\left(6 \mathrm{lb} / \mathrm{ft}^{3}\right)$ as compared with standard polyurethane at $24 \mathrm{~kg} / \mathrm{m}^{3}\left(1.5 \mathrm{lb} / \mathrm{ft}^{3}\right)$. It has been estimated that replacement of all the cabin seat polyurethane seat cushioning with neoprene foam would impose a weight penalty of about $907 \mathrm{~kg}(2000 \mathrm{1b})$ for a wide-body jet aircraft. Hence, the use of the foamed neoprene as a fire layer between the fabric and polyurethane foam may be the only way in the short term to control fire propagation through the aircraft interior of contemporary design.

It has been estimated from recent preliminary tests that optimization with regard to blocking-layer thickness and position of the heat-blocked seats in the aircraft could result in a weight penalty for the wide-body transport of between 68 and $136 \mathrm{~kg}(150-300 \mathrm{lb})$. When a neoprene foam is used as a fireblocking interlayer in a thickness of $1.3 \mathrm{~cm}(0.5 \mathrm{in.})$ between the seat covering and the polyurethane foam, it has been found that this configuration results in no fire propagation at a $2 \mathrm{~W} / \mathrm{cm}^{2}$ radiant heat source with a freeflame-ignition source about as well as an all neoprene seat. Surprisingly, few if any of the irritating gases normally expected from the pyrolysis of chloroprene (e.g., hydrogen chloride) have been observed in cabin fire simulator tests. It has also been observed that the neoprene fire-blocking layer covering the polyurethane and covered with wool-nylon fabric seems to surpress the flame spread across the fabric. It may be conjectured that the low-smoke neoprene not only protects the underlying cushioning foam but also, through char-swelling and hydrogen chloride evolution, inhibits flame spread of the fabric covering. These fire-suppression mechanisms observed in the cabin-fire simulator may be of considerable importance in preventing fire propagation into the aircraft interior ceiling, as was observed in the $\mathrm{C}-133$ baseline test.

A sketch of an advanced seat concept is shown in figure 11 . This seat has been designed with the best material options available, both with respect to functionality and to fire resistance; it has been described by Fewell et al. (ref. 27). It takes advantage of an imide foam with a somewhat lower density than standard polyurethane but with a much reduced flammability. Since this low density polyimide foam may still require some fire-blocking protection, a neoprene foam fire-blocking layer has also been included. A wool-kermel blend rather than wool-nylon is used in this advanced seat to further reduce the flame spread from external ignition sources. 
A three-seat array of this advanced seat is shown in figure 12 . It is planned to evaluate seats of this kind at higher heating rates than $3 \mathrm{~W} / \mathrm{cm}^{2}$ in the Douglas Aircraft cabin-fire simulator as a back-up for the fireblocking neoprene-polyurethane system, especially for the case of outboard seats.

It may be concluded that the most cost-effective option available in the short term to break the fire chain generated by the external postcrash fire as it attempts to penetrate the interior system through a damaged fuselage or open door may be the use of a neoprene fire-blocking layer in contemporary seats. Neoprene foams in the form of vonar and 1ow-smoke L-200 are commercially available and only somewhat more expensive than currently used polyurethane cushioning. It is believed that the weight penalty incurred by using the neoprene layer can be minimized by designing the thickness to accomodate the fire sources encountered in a survivable postcrash fire. Special material options are available using the neoprene fire-blocking layer with no significant weight penalty. Application of the NASA charring materials ablation code, CMA, is available (ref. 28) and is being modified to optimize these systems. The radiant panel facilities available in the Douglas Aircraft cabin-fire simulator and the Ames postcrash fire simulator can be used to evaluate this optimization technique.

\section{WINDOW SYSTEMS FOR POSTCRASH FIRE PROTECTION}

It has been reported by SAFER (ref. 1) that the contemporary panels of a wide-body transport aircraft provide sufficient protection to prevent fire penetration of the fuselage when exposed to an external fuel fire of very short duration. However, the present acrylate window systems shrink, as should be expected, and drop out, allowing direct fire penetration long before the failure of the airframe structure. Earlier, Bricker and Duskin (ref. 25) demonstrated that contemporary polymethyl methacrylate windows were burned through in 50 to $60 \mathrm{sec}$ under the heat flux typically encountered in a postcrash fire.

Parker et a1. (ref. 29) have developed physically equivalent windows, composed of a high-char-yield epoxy trimethoxyboroxine transparent polymer system, that resist burn-through for up to $10 \mathrm{~min}$. Eklund et a1. (ref. 30) confirmed that state-of-the-art windows do indeed shrink and fall out in less than $1 \mathrm{~min}$, whereas the high-yield windows do not fall out but survive for at least $6 \mathrm{~min}$.

A generalized plot of window performance is shown in figure 13. Here the back-side temperature change with time is plotted for contemporary windows, which burn through (as shown) in 1.5-2 min. It can be seen that the advanced materials provide continuing protection at times greater than 8 min. In comparing the slopes of the temperature-time plots the superior ablation efficiency of the new high-char-forming windows is apparent. In order to apply this fire resistant transparent window to maximize the window systems functionality, that is, scratch, ultraviolet resistance, etc., and provide a 
fireworthy window system design, it has been necessary to apply the new window material as interlayer with fire hardened edge attachment as shown in figure 14. This type of assembly has been developed into full-scale canopies for military aircraft.

Various options have been examined to apply this fire-resistant transparent material to a conventional window system (fig. 15). It is now believed that the most effective and practical way to use the epoxy window as a fire barrier is as the secondary fail-safe inner window shown in figure 16 . of course, similar fire-resistant edge-attachment methods as shown for the military canopy will have to be applied to optimize the fire performance of these new candidate windows.

\section{DATA BASE LIBRARY FOR AIRCRAFT INTERIOR MATERIALS}

The purpose of the study is to provide NASA and the FAA with several design options for a library of data for materials that are currently or can potentially be used in aircraft interiors.

It was recognized that for many years the aircraft community has been studying the contribution of materials used in aircraft interiors to aircraft fire safety. Although the fire safety record in commercial aircraft has been continuously improved there is an ongoing attempt to alleviate the threat of severe aircraft cabin fires with state-of-the-art technology and new material developments. It is the responsibility of government organizations such as the FAA to regulate the introduction of new materials to aircraft interior use based on the material's contribution to the fire hazard. In order to effectively regulate the use of new materials, these organizations must recognize and evaluate the potential benefit and associated costs of utilizing them in the cabin interior. However, data on the material's fire performance, cost, processing, and maintenance, which must be utilized in this evaluation, are not available in a centralized repository.

The SAFER Committee recognized the need to select materials for aircraft applications that would provide the highest performance in a fire scenario while still meeting design and cost criteria. The Committee also recognized the lack of agreed-upon standard tests and fire threat scenarios, the proprietary nature of industry materials data, the continuing development of hundreds of new materials per year, and the lack of a large-scale, computer-based "clearing house" or data base for these materials and their properties.

Data about aircraft materials are generated by many members of the materials and aircraft community, including material suppliers, aircraft manufacturers, and government organizations involved in R\&D, testing, and the development of standards. While some of the data are published and therefore distributed to other interested groups, much of it is available only to the group generating the data. To decrease the redundancy in testing and to distribute the information required for material evaluation, the SAFER Committee agreed that a centralized repository for these data should be established by the FAA. 
In addition, there are conflicting viewpoints as to which testing methods should be used in materials evaluation and selection. It is recognized that a centralized data repository would provide an improved ability to compare test results from different test methods and therefore facilitate decisions about the most desirable testing methods.

The study is organized into three major tasks aimed at generating several design options for the data base. The design options will be defined by the data contents, data suppliers, required administrative support, applicable computer software and hardware, and various plans for user accessibility.

The first task is to survey potential users of the data base and suppliers of data, with emphasis on characterization of the data that is both desired and available. The kinds of data potentially to be contained with the data library include:

1. Material descriptions

2. Fire performance properties

3. Physical properties

4. Mechanical properties

5. Processing and maintenance characteristics

6. Cost information

The second task involves four subtasks aimed at estimating the requirements, in terms of manpower and cost, for configuring a data base to respond to the needs of the potential user community. Included in task 2 is a survey of applicable commercial software and hardware to select those systems which may be appropriate to the various options. This task results in a recommendation to NASA and the FAA of the most effective and efficient library configuration (s).

Task 3 reviews the anticipated applications of the materials data library and will be performed in conjunction with the first two tasks. Figure 16 shows an outline of the three major tasks and their subtasks.

The study has proceeded on schedule during the first 3 months. ECON has indicated that initial design-option descriptions and cost estimates will be completed by early November. These design options will incorporate the results of the surveys of potential data-bank users and data suppliers and the screening of commercially available computer hardware and sof tware that are now in progress. At such time these initial options will be presented to Ames Research Center and to the FAA Test Center for preliminary review and discussion.

\section{CONCLUDING REMARKS}

It has been shown in this paper that there exists a substantial technology base for the selection, evaluation, and application of fire-resistant subsystem components that can reasonably be expected to improve human survivability in 
aircraft fires involving aircraft interiors. This technology can, in the short term, effect improvements in aircraft fire safety as well as provide a sound basis for further long-term improvements in new aircraft. 


\section{REFERENCES}

1. Final Report of the Special Aviation Fire and Explosion Reduction Advisory Committee (SAFER), June 1980.

2. Aviation Safety - Interior Compartment Materials. Hearings before the Subcommittee on Oversight and Review of the Committee on Public Works and Transportation, House of Representatives, 96th Congress, U.S. CPO Report 96-12, Apri1 1979, p. 61.

3. Sarkos, C. P.; and Hil1, R. G.: Preliminary Wide Body (C-133) Cabin Hazard Measurements During a Postcrash Fuel Fire. Federal Aviation Administration, National Aviation Facilities Experimental Center, Report No. NA-78-28-LR, 1978.

4. Study of Aircraft Crashworthiness for Fire Protection. Douglas Aircraft Co., Interim Report, NASA Contract NAS2-10583, Ju1y 1980.

5. Neel, C. B.; Parker, J. A.; and Fish, R. H.: Heat Shields for Aircraft: A New Concept to Save Lives in Crash Fires. Astronaut. \& Aeronaut., Nov. 1971.

6. Kourtides, D. A.; Parker, J. A.; et a1.: Fire Containment Tests of Aircraft Interior Panels. Journal of Fire and Flammability, Apr. 1976.

7. Radiant Panel Tests. ASTM report E 162-67.

8. Parker, J. A.; Kourtides, D. A.; Fish, R. H.; and Gilwee, W. J.: Fire Dynamics of Modern Aircraft from a Materials Point of View. Proceedings of the AGARD Propulsion and Energetics Panel, Rome, Italy, Apr. 1975.

9. Combined Hazards Index. Interim Report, Douglas Aircraft Co., FAA Technical Center Contract, 1979.

10. Parker, J. A.; and Winkler, E. L.: The Effects of Molecular Structure on the Thermochemical Properties of Phenolics and Related Polymers. NASA TR R-276, 1967.

11. Kourtides, D. A.: Flammability and Thermochemical Properties of Some Thermoplastics and Thermoset Polymers - A Review. Journal of Polymer Plastics Technology and Engineering, vol. 11, no. 2, 1978, pp. 159-198.

12. Van Krevelen, D. W.: Some Basic Aspects of Flame Resistance of Polymeric Materials. Polymer, vol. 16, 1975, p. 615.

13. Kourtides, D. A.; Parker, J. A.; and Hilado, C. J.: Thermochemical Characterization of Some Thermoplastic Polymers. Journal of Fire and Flammability, vol. 8, no. 1, 1977, pp. 59-95. 
14. Fish, R. H.; and Parker, J. A.: The Performance of Lightweight Plastic Foams Developed for Fire Safety. Proceedings of the NASA Conference on Materials for Improved Fire Safety, May 10, 1970, pp. 11-1/11-20.

15. Hilado, C. J.; Kourtides, D. A.; Barnes, G. J.; and Parker, J. A.: The Use of the High Flux Furnace in the Smoke Chamber to Measure Ignitability and Smoke Evaluation of Composite Panels. Journal of Fire and Flammability, vol. 8, no. 3, 1977.

16. Riccitiello, S. R.; Fish, R. H.; Parker, J. A.; and Gustafson, E. J.: Development and Evaluation of Modified Polyisocyanurate Foams for Low Heating Rate Thermal Protection. Proceedings of the 28th ANTEC-SPE Conference, May 1970 .

17. Williamson, R. B.: Large Scale Fire Testing of Aircraft Interiors: Construction and Development of Criteria to Represent the Level of Threat. University of California, Berkeley, NASA Grant Interim Report NSG-2026-A.

18. Anderson, R. A.; Arnold, D. B.; and Johnson, G. A.: Development of Aircraft Lavatory Compartments with Improved Fire Resistance Characteristics. NASA CR-152120, 1979.

19. Polyether Ether Ketone Provisional Data Sheet. ICI Plastics Division, PJK/AGS/CM, Nov. 1979 (Ref. No. PK PD7).

20. Kourtides, D. A.; Parker, J. A.; et a1.: Thermophysical and Flammability Characterization of Phosphorylated Epoxy Adhesives. Proceedings of the Adhesives for Industry Conference, Society of Plastics Engineers, Los Angeles, Calif., June 1980.

21. Engineering and Development Program Plan - Aircraft Cabin Fire Safety. U.S. Dept. of Transportation, Federal Aviation Administration, Report No. FAA-E-18-7, June 1980.

22. Hill, R. G.; and Sarkos, C. P.: Postcrash Fuel Fire Hazard Measurements in a Wide Body Aircraft Cabin. Journal of Fire and Flammability, vol. II, apr. 1980, pp. 151-163.

23. Eklund, T. I.: Preliminary Evaluation of the Effects of Wind and Door Openings on Hazard Development Within a Model Fuselage from an External Pool Fire. Federal Aviation Administration, NAFEC, Letter Report NA-79-1-LR, Feb. 1979.

24. Hartze11, G.: Fire Test Methodology for Aerospace Materials. Southwest Research Institute, NASA Final Report NAS-10140.

25. Bricker, R. W.; and Duskin, F.: 737 Aircraft Flammability Testing. NASA TM-78523, 1978. 
26. Pope, R. B.; Riccitiello, S. R.; and Parker, J. A.: Evaluation of a Polyurethane Foam for Ablative Protection at Low Heating Rates.

J. Spacecraft \& Rockets, vo1. 6, 1968, p. 74.

27. Fewel1, L. L.; Duskin, F.; et a1.: Release-Rate Calorimetry of Multilayered Materia1s for Aircraft Seats. SAMPE Quarterly, Apr. 1980.

28. Analytical Modeling of Intumescent Coating Thermal Protection System in a JP-5 Fuel Fire Environment. Aerothern Final Report, NASA Contract NAS2-7709, June 1974.

29. Parker, J. A.; Fohlen, G. M.; and Sawko, P. M.: Development of Transparent Composites and Their Thermal Responses. Presented at Conference on Transparent Aircraft Enclosures, sponsored by Air Force Materials Laboratory and Air Force Flight Dynamics Laboratory, Las Vegas, Nev., Feb. 5-8, 1973.

30. Eklund, Thor I.; Wright, Joseph A.; Fann, Franklin D.; and Berenotto, Joseph F.: Preliminary Evaluation of the Performance of Advanced and Conventional Aircraft Windows in a Model Fire Environment. NAFEC Technical Letter Report NA-80-17-LR, Federal Aviation Administration, Atlantic City, N.J. 


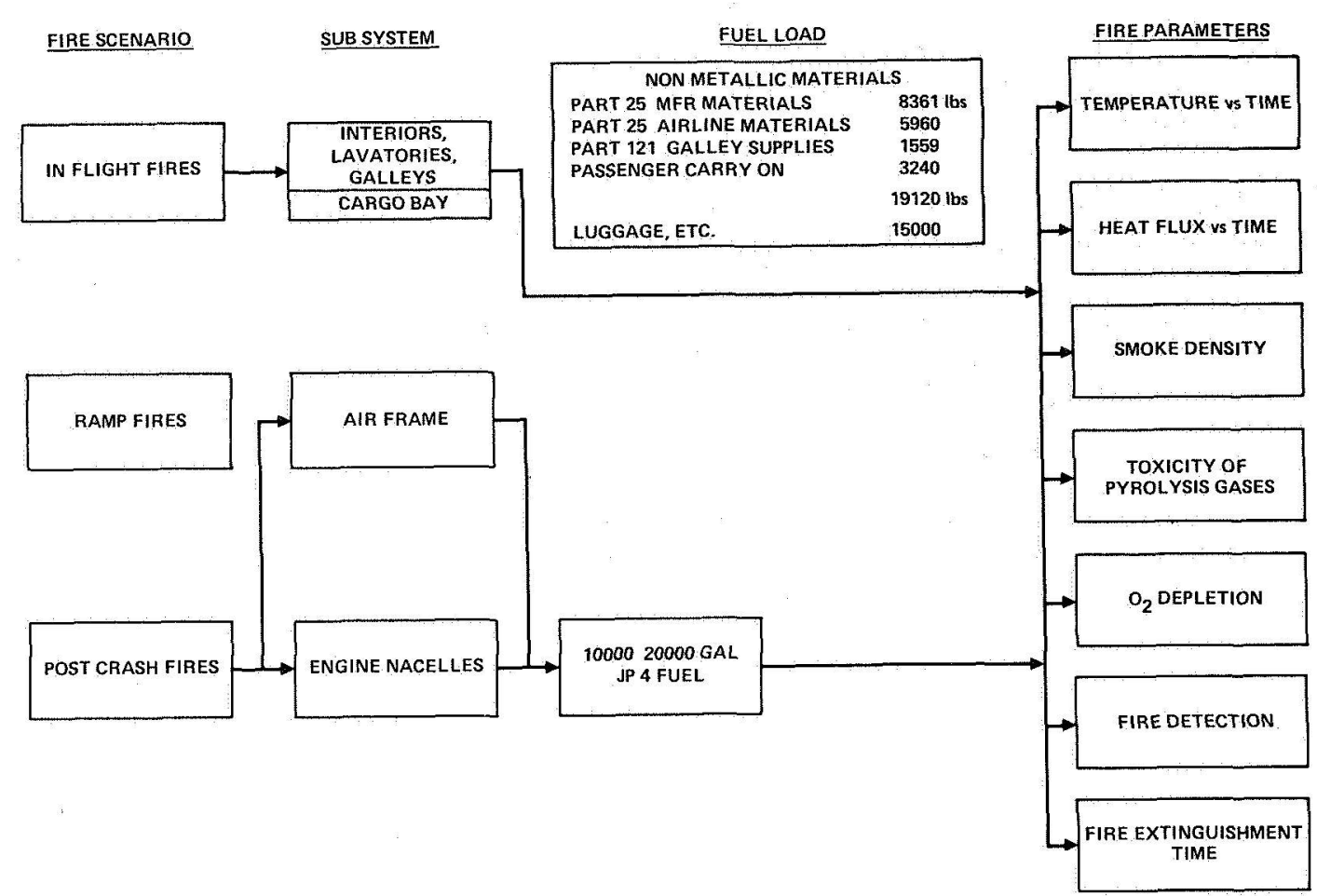

Figure 1.- Survivability criteria for aircraft fires (270 passenger aircraft). (Note: $11 \mathrm{~b}=0.454 \mathrm{~kg}$ and 1 gal $=0.378$ liters.)

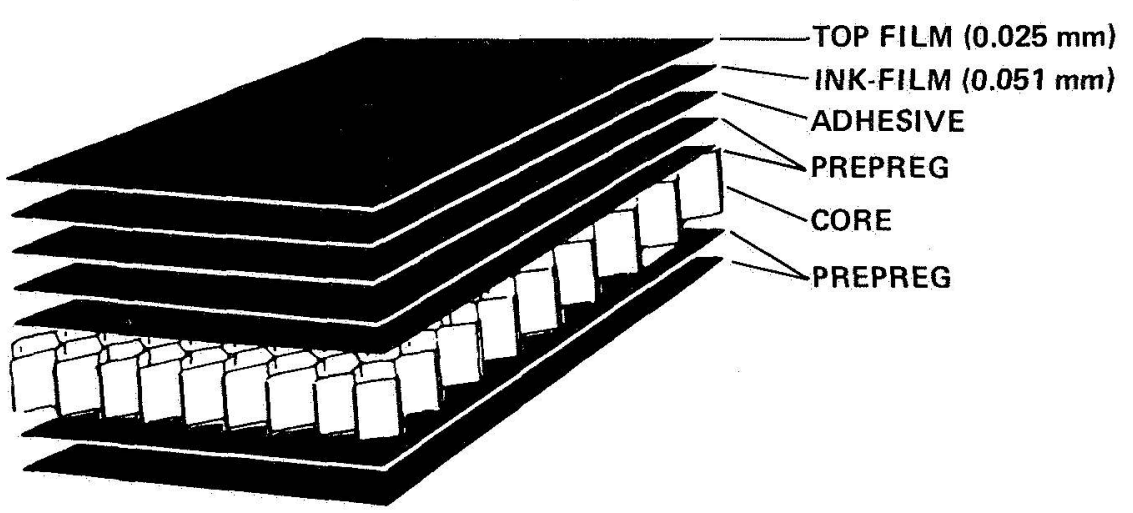

- CANDIDATE RESIN SYSTEMS for PREPREg

- BASELINE EPOXY

- BISMALEIMIDE

- PHENOLIC

- POlyIMIDE

- testing matrix

- flammABILITY, SMOKe, AND TOXICITY

- MECHANICALS AND AESTHETICS

Figure 2.- Sandwich panel configuration. 


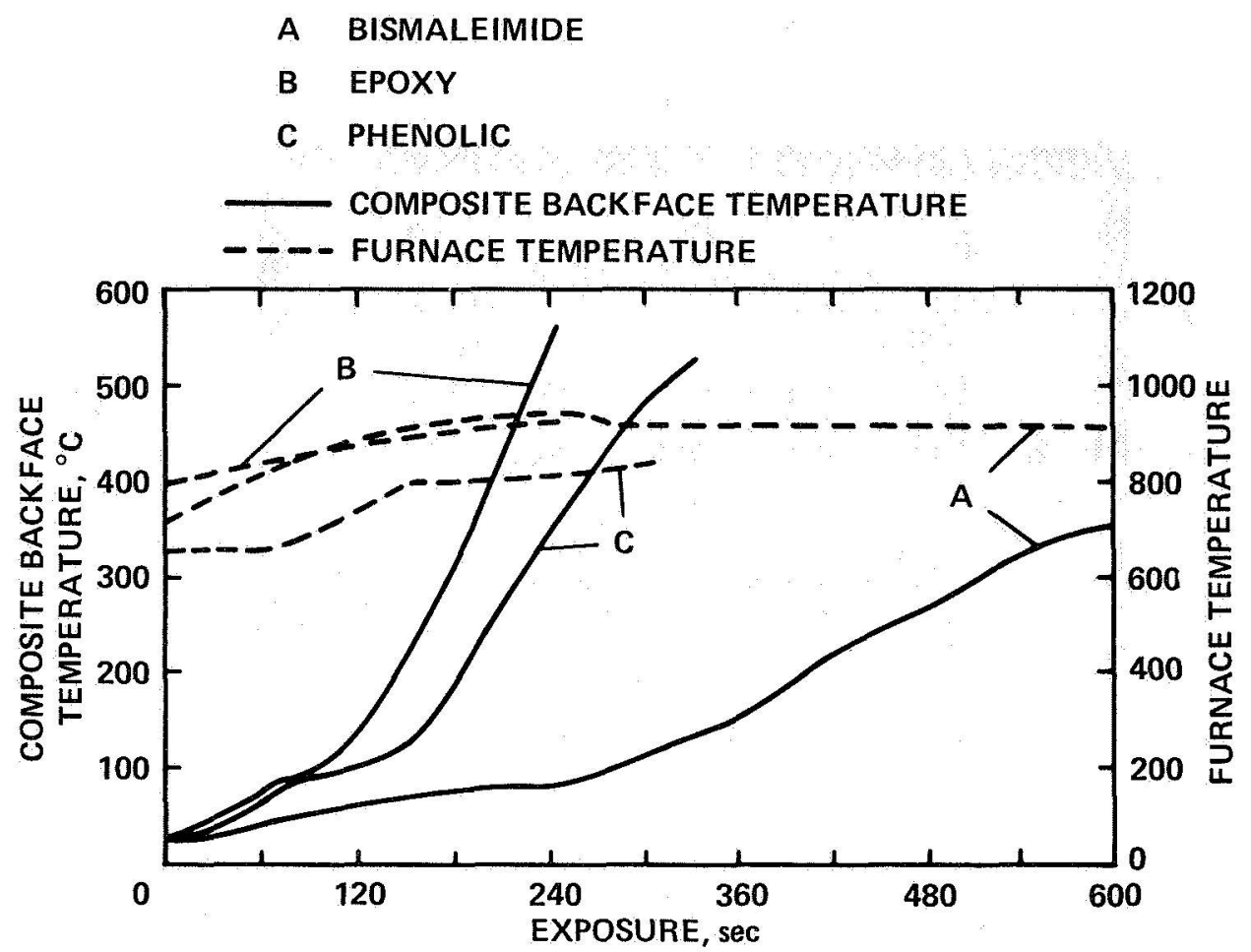

Figure 3.- Thermal efficiency of panels.

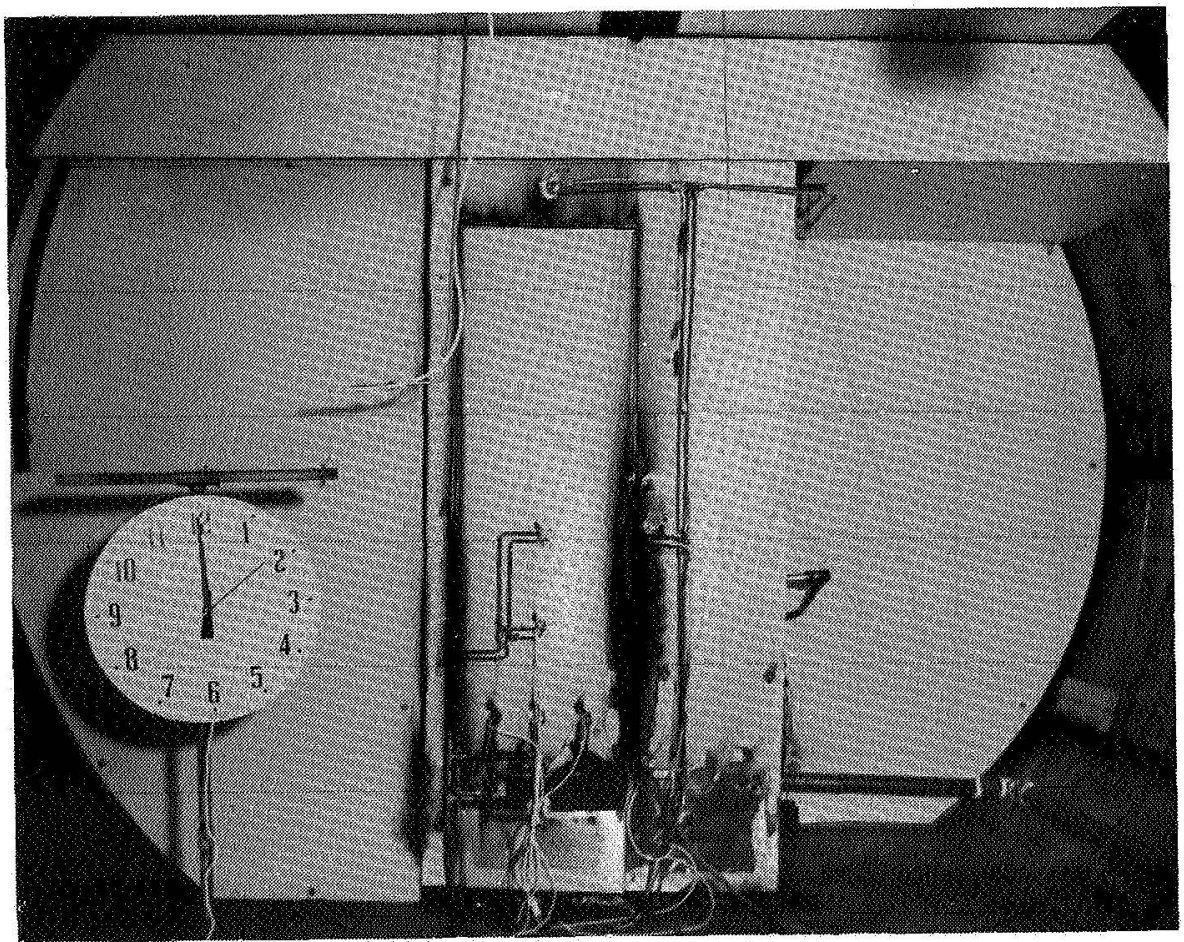

Figure 4.- Laboratory setup in cabin fire simulator. 


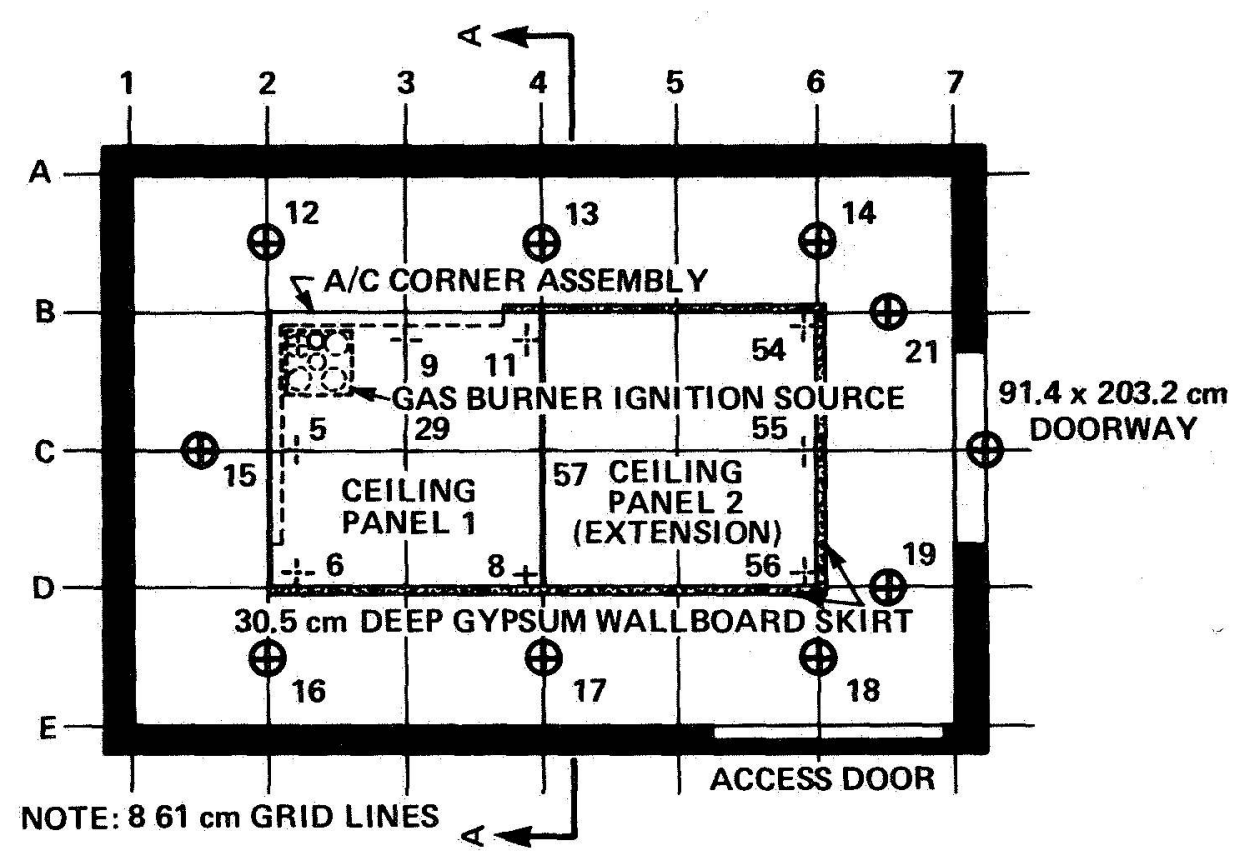

(1) THERMOCOUPLE $2.5 \mathrm{~cm}$ BELOW COMPARTMENT CEILING

-i- THERMOCOUPLE $2.5 \mathrm{~cm}$ BELOW CORNER ASSEMBLY CEILING

Figure 5.- Flashover test facility.

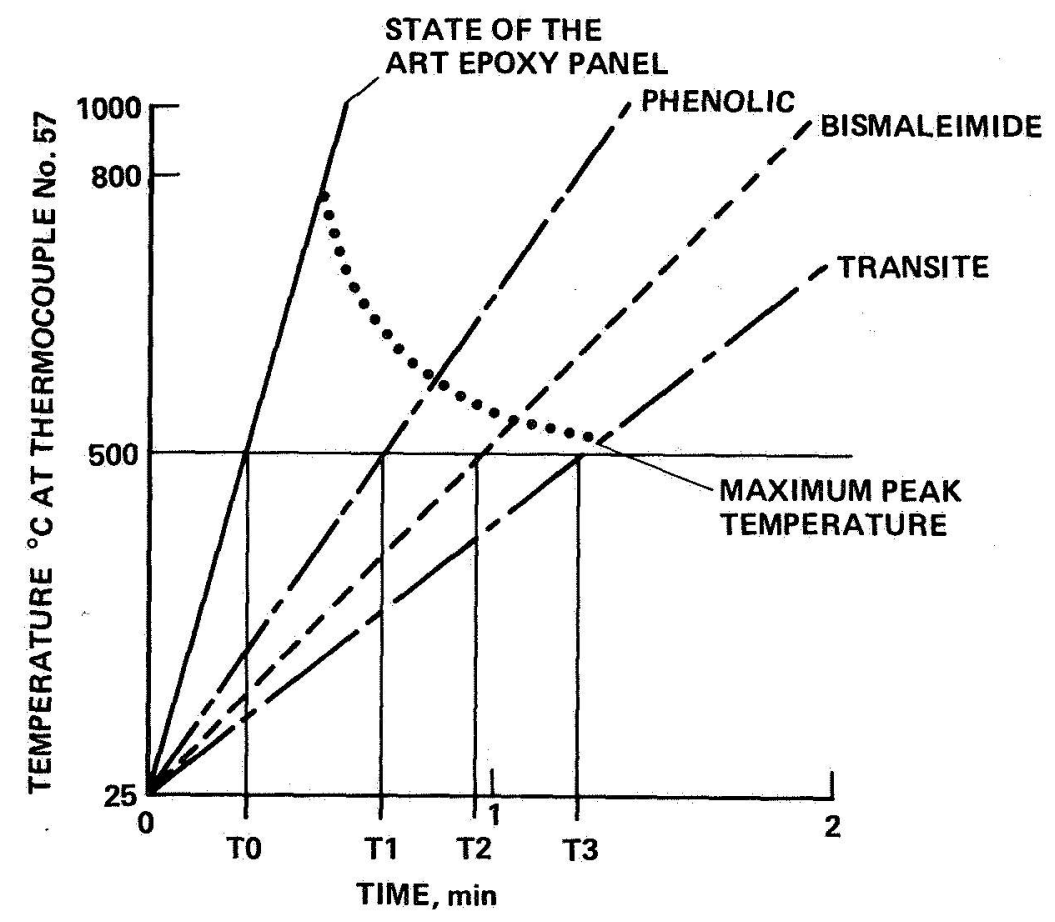

Figure 6.- Center point ceiling temperature as function of time for Transite, state-of-theart epoxy, and advanced resins. 
- LABORATORY TESTS-WEIGHT DISTRIBUTION

- FLAMMABILITY-10\%

- SMOKE EMISSION-20\%

- TOXIC GAS EMISSION-10\%

- HEAT RELEASE-20\%

- HEAT RELEASE RATE-20\%

- THERMAL CONDUCTIVITY-4\%

- MECHANICAL STRENGTH-6\%

- DENSITY-10\%

- MATERIAL AND FABRICATION

- $15 \%$

- LABORATORY TESTS-85\%

Figure 7.- Ranking procedure.

BASELINE DEVELOPED

EPOXY PHENOLIC

- PROPENSITY TO BURN (LOI)

- FACE SHEET

- BOND PLY
29.0

27.7
$100^{+}$

53.5

- SMOKE EMISSION (D $@ 4 \mathrm{~min})$ NBS

- $2.5 \mathrm{~W} / \mathrm{cm}^{2}$

- $5.0 \mathrm{~W} / \mathrm{cm}^{2}$

62.8

2.5

96.5

8.4

- HEAT RELEASE (J/cm $\left.{ }^{2}\right)$ OSU

- $2.5 \mathrm{~W} / \mathrm{cm}^{2}$

- $5.0 \mathrm{~W} / \mathrm{cm}^{2}$

177.2

512.4

126.0

96.3

- CHAR YIELD, $800^{\circ} \mathrm{C}, \mathrm{N}_{2}, \%$

38.0

61.0 


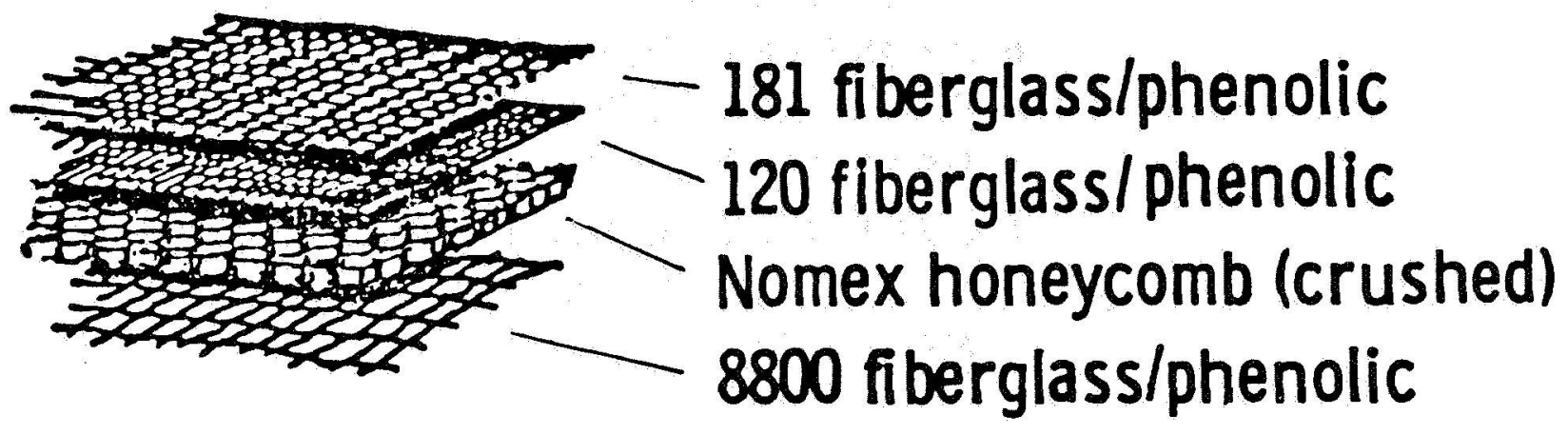

Figure 9.- Crushed-core sandwich panel.

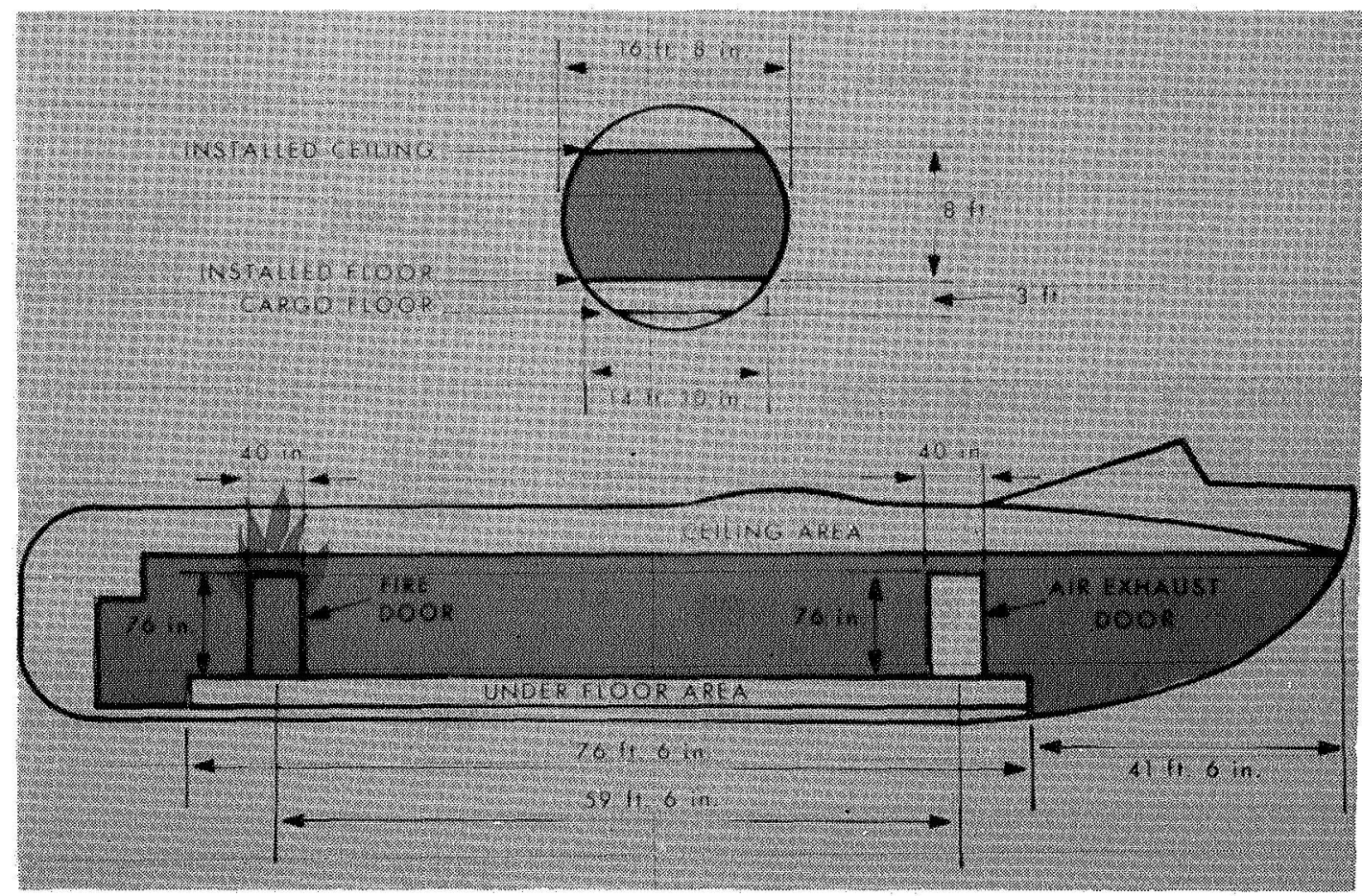

Figure 10.- C-133 wide body cabin fire test article. (Note: $1 \mathrm{ft}=0.3048 \mathrm{~m}$.) 
-CONSTRUCTED FROM MOST ADVANCED FIRE-RESISTANT MATERIALS AVAILABLE

- APPROXIMATELY $0.5 \mathrm{~kg}$ HEAVIER THAN CONVENTIONAL URETHANE CUSHION DESIGNS

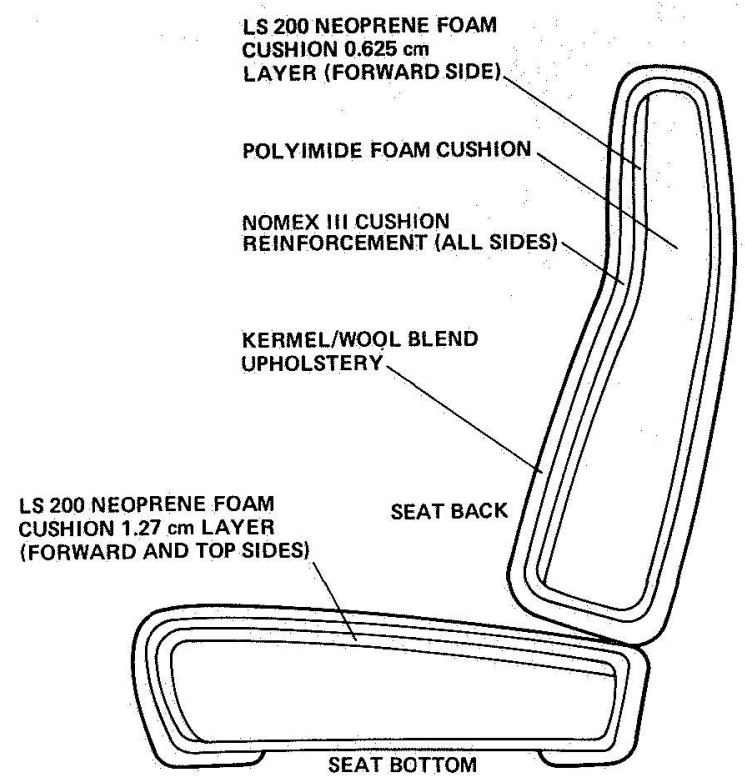

Figure 11.- NASA fire-resistant passenger seat cushion construction.

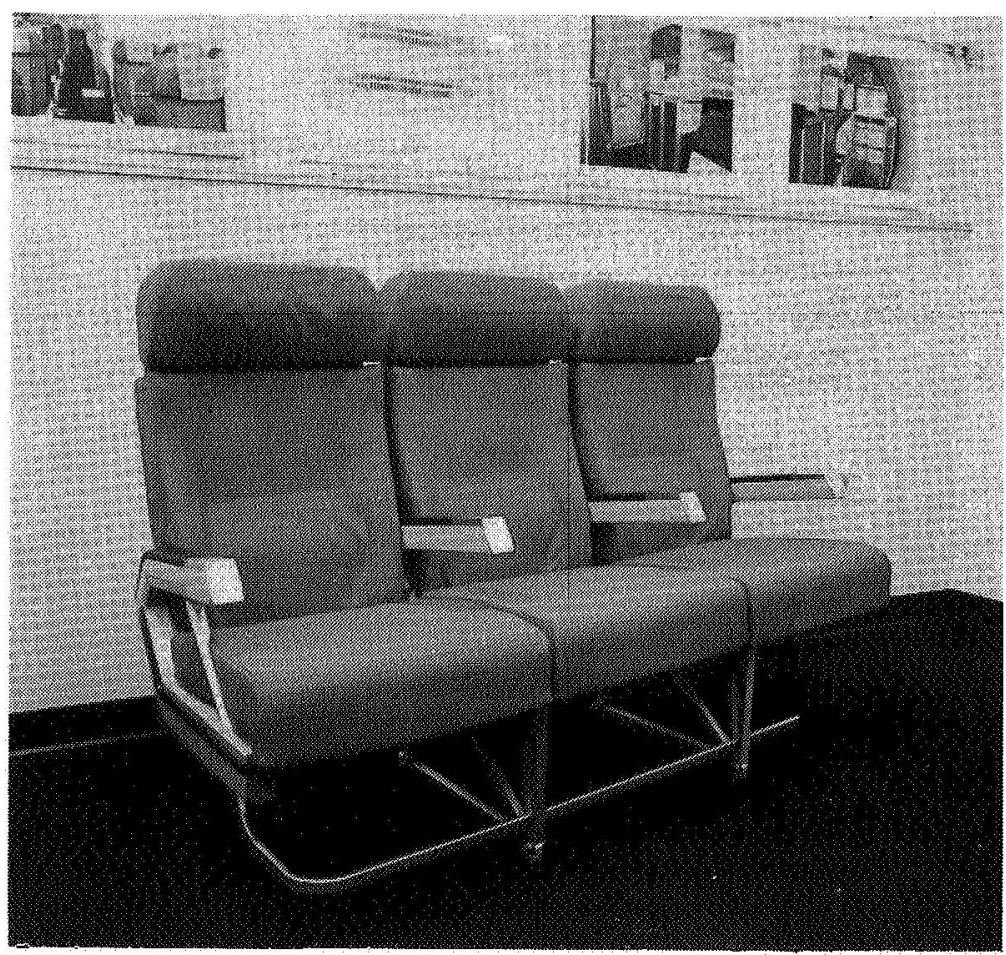

Figure 12.- Three-seat array of advanced seats. 


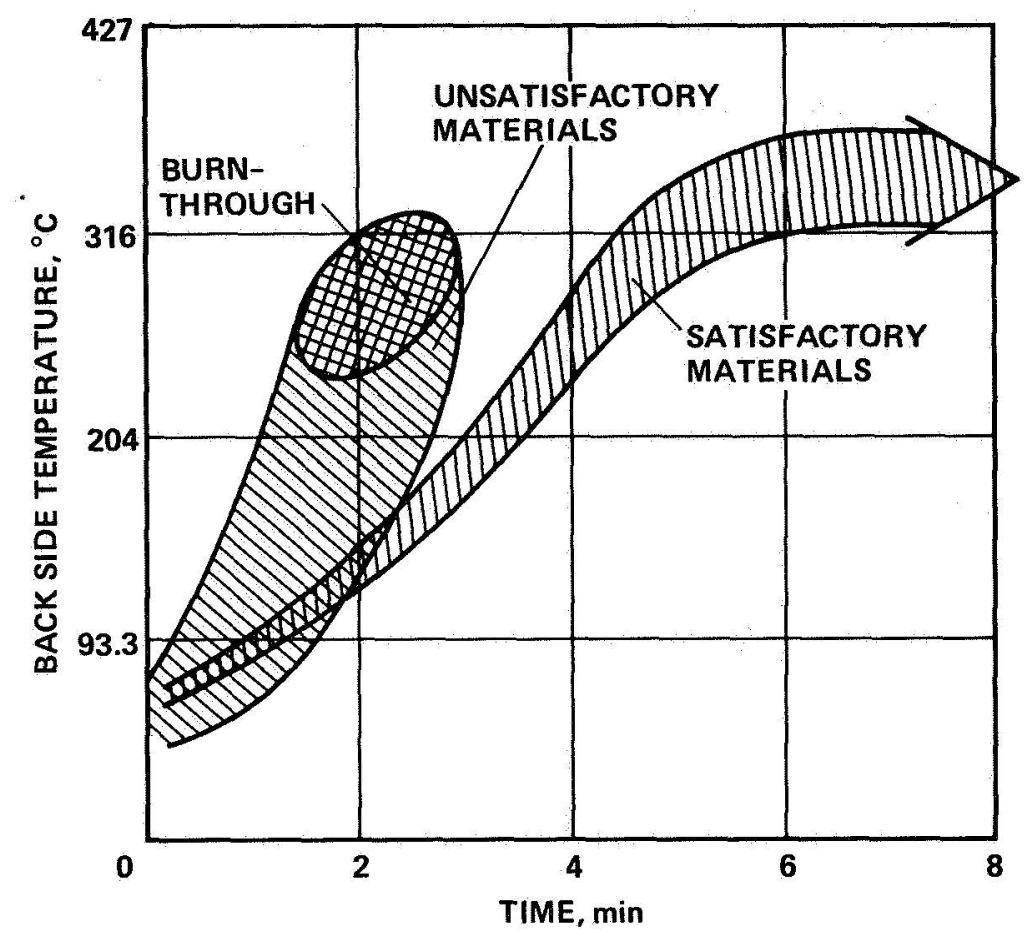

Figure 13.- General data plot of Ames Research Center's T-3 fire test results.

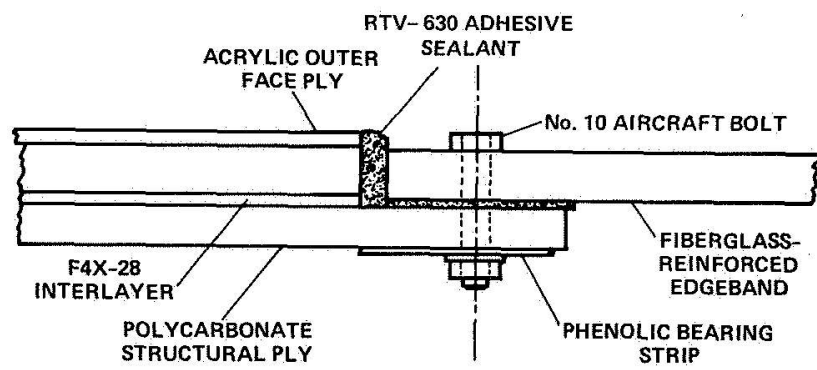

DETAILS OF EDGE ATTACHMENT DESIGN

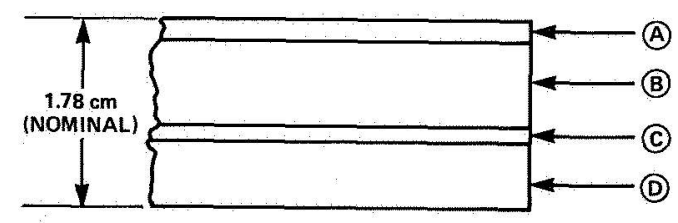

(A) $2.03 \mathrm{~cm}$ OUTER PLY OF ACRYLIC

(B) $0.813 \mathrm{~cm}$ EX-112 PLY DIRECTLY BONDED TO THE ACRYLIC

(C) $0.127 \mathrm{~cm}$ OF SILICONE INTERLAYER

(D) $0.635 \mathrm{~cm}$ POLYCARBONATE STRUCTURAL PLY

Figure 14.- Fire-resistant transparent composite. 

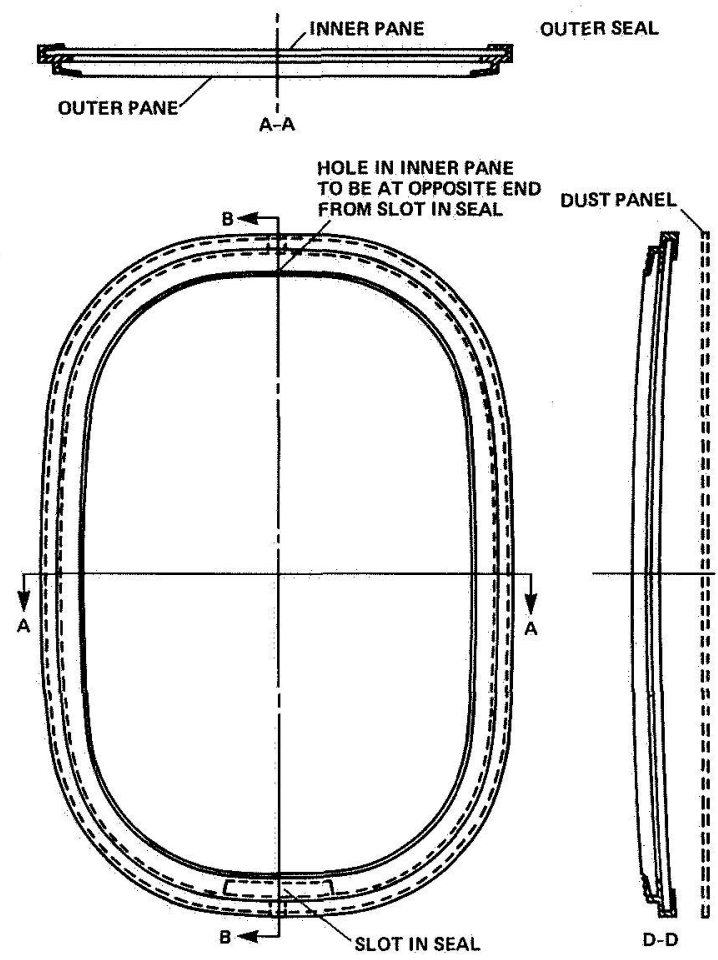

Figure 15.- Air transport passenger window.

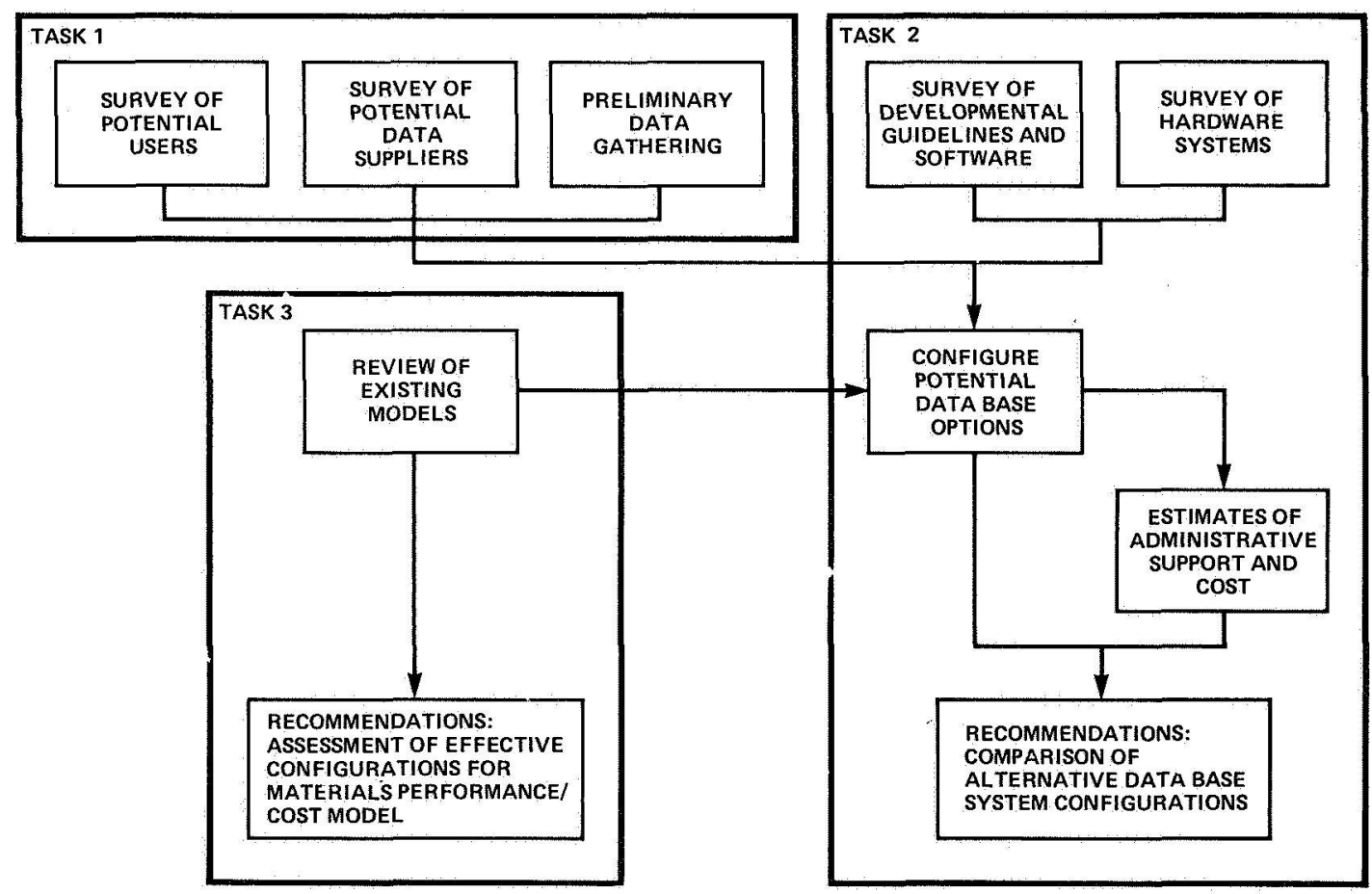

Figure 16.- Overview of study tasks. 


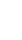

